\title{
Important aspects of Demodex diagnostics
}

\author{
Alexey Kubanov A ${ }^{1}$, Gallyamova Yulia ${ }^{2}$, Anzhela Grevtseva ${ }^{2 *}$ \\ ${ }^{1}$ State Scientific Center of Dermatovenereology and Cosmetology, Ministry of Healthcare of the Russian Federation, Moscow, Russia \\ ${ }^{2}$ Russian Medical Academy of Postgraduate Education, Ministry of Healthcare of the Russian Federation, Moscow, Russia
}

\begin{abstract}
The article presented our reviews on methodological advances in the diagnosis of demodecosis via our own research on demodecosis diagnosis efficiency with the aid of fluorescence lifetime measurement using confocal laser scanning microscopy. Under our supervision, there were 60 patients with acne and rosacea complicated with demodecosis, 60 patients with acne and rosacea without demodecosis, and 30 healthy volunteers. All patients underwent skin scraping and epilation of eyebrows and/or eyelashes, and the examination of skin morphology was conducted using confocal laser scanning microscopy. The research has shown the advantages of in vivo confocal laser scanning microscopy over the conventional microscope.
\end{abstract}

Keywords: demodex; demodecosis; Demodex mites; confocal laser scanning microscopy; acne; rosacea

Citation: Kubanov A, Gallyamova Y, Grevtseva A. Important aspects of Demodex diagnostics. J Surg Dermatol 2020; 5(2): 42; http://dx.doi.org/10.18282/jsd.v1.i1.42.

*Correspondence to: Anzhela Grevtseva, Russian Medical Academy of Postgraduate Education, Ministry of Healthcare of the Russian Federation, Barrikadnaya Str., 2/1, Moscow, 123995, Russia; agrevtseva@ mail.ru.

Received: $12^{\text {th }}$ January 2019; Accepted: $6^{\text {th }}$ February 2020; Published Online: $18^{\text {th }}$ February 2020

\section{Introduction}

Demodecosis is a skin disease caused by a group of parasitic and opportunistic mites from the group of acariasis known as Demodicidae (Demodex folliculorum longus and Demodex folliculorum brevis). The mites with the size of 0.2-0.5 mm live in sebaceous and meibomian glands, which are in the hair follicles of humans and mammals. According to various sources, the incidence of demodecosis is from $2 \%$ to $5 \%$ and is ranked at the seventh place in terms of frequency among skin diseases. In terms of the structure of acneiform dermatoses, $10.5 \%$ are classified as demodecosis.

Despite the fact that mites on human skin are part of skin microflora, they do not cause any clinical symptoms and complaints in the vast majority of people; however, they maintain the acuity of the inflammatory process in dermatoses such as acne, rosacea, seborrheic dermatitis and perioral dermatitis, which may also cause distinct diseases ${ }^{[1]}$. In the presence of Demodex, clinical mani- festation may acquire a more pronounced characterization with the prevalence of papulopustules elements, diffusive erythema, formative stages of granulomas, nodular elements and macro-abscesses ${ }^{[1]}$. In 1903, Stcherbatchoff $\mathrm{N}$ found mites in ciliary follicles of eyelids of a person, in which, these mites play a vital role in the development of blepharitis and blepharoconjunctivitis, as cited by Whiting $\mathrm{DA}^{[2]}$. Interestingly, different types of mites cause different clinical manisfestations, which presumably are connected to the size of the mites themselves. Detection of both Demodex folliculorum longus and Demodex folliculorum brevis often observed erythema and desquamation of epithelium, and symmetric papulopustules elements, respectively ${ }^{[3]}$. Long-term chronic demodecosis is characterized by skin thickening, a feeling of constriction, decreased elasticity and softness, and presence of serous or saniopurulent crusts ${ }^{[4]}$.

According to the International Classification of Diseases, 10th Revision, demodecosis can be attributed under code B88.0, i.e., in the subgroup of "other acariasis"

Copyright $\odot 2020$ Kubanov A, et al. This is an Open Access article distributed under the terms of the Creative Commons Attribution-Non Commercial 4.0 International License (http://creativecommons.org/licenses/by-nc/4.0/), permitting all non-commercial use, distribution, and reproduction in any medium, provided the original work is properly cited. 
including demodecosis acarodermatitis, which is a type of dermatitis caused by Dermanyssus gallinae, etc. By all means, the diagnosis of demodecosis is possible only after the establishment of laboratory diagnostics which find mites of the genus Demodex.

The most common method of laboratory diagnostics is based on the preparation of acarogram by counting larvae, nymphs, eggs and mites in adult stage. The criterion of mites activity is that the number of mites must be more than 5, with larvae or eggs on $1 \mathrm{~cm}^{2}$ of the infected area. In the diagnosis of demodecosis of the eyelashes, the detection of a mite on 2-4 eyelashes is considered as normal. In order to evaluate the effectiveness of the therapy, repeated acarogram is carried out for the purpose of counting the number of mites and determining their activity. The activity of mite infestation can be measured through changes in the number of mites per 1 $\mathrm{cm}^{2}$ of the infected area. It is known that the course of treatment of demodecosis can move into the untreated zones via acaricide means. In such cases, more often than not, the mites are located at the edge of the scalp ${ }^{[4]}$.

Technically, the procedure of mite detection is quite simple. Demodex is possibly detected by scraping during the extraction of ducts' contents of sebaceous glands, or by removing the eyelashes and/or eyebrows without damaging the hair follicles. Skin scraping is conducted by means of disposable scalpel at places where the greatest congestion of Demodex reside (forehead, wings of nose, and chin). The tested material is placed on a glass slide with a $10 \%$ alkaline solution $(\mathrm{KOH})$, covered with a glass slide and examined under the microscope at low magnification. The advantage of this method is its ability to analyze large affected areas, as well as removing mites not only from the surface of the skin but also directly from the sebaceous glands. However, there is a problem: it is not always possible to detect mites deeper in the sebaceous glands. Another disadvantage is the epithelium trauma, which is associated with the relative painfulness of the procedure and the discomfort in patients after epilation ${ }^{[4]}$. It should be noted that information on scraping method is less abundant, and negative analysis result of laboratory research does not prove the absence of mite infestations ${ }^{[5]}$.

There are other ways of detecting mites, such as carrying out surface biopsy ("scotch tape test") ${ }^{[5,6]}$. A drop of cyanoacrylate adhesive (BF-6, sulfacrylate) is placed on an oil-free cover glass, and then pasted onto the affected surface for $1 \mathrm{~min}$. After its removal from the affected surface, the alkaline solution is applied, covered with a glass slide and examined under the microscope at low magnification. The modification of the procedure is in the use of scotch tape, with the size of $1 \mathrm{~cm}^{2}$, adhered onto the cover glass on the alkaline solution after its removal. Upon removing the cover glass or adhesive tape, the surface layer of the epidermis and the contents of sebaceous glands with the existing mites remain on the surface. The advantage of the method is its ease of use, but skin epithelium trauma, difficulty in obtaining material from the nose wings, and incomplete sterility of the obtained samples are clear disadvantages ${ }^{[4]}$.

A more difficult method of demodecosis diagnosis is carrying out a skin biopsy with subsequent histology of the received samples. For this purpose, a small skin area is obtained either by puncture (punch) or excisional (scalpel) method, fixed within a day in $10 \%$ neutral formalin solution, compacted with paraffin and stained with hematoxylin-eosin. Histological study provides many advantages; in particular, it is possible to fully see the sebaceous glands and surrounding areas. The main disadvantages of this method include skin trauma with the formation of scar and the inability to examine a large area of the $\operatorname{skin}^{[4]}$.

As a diagnostic tool to identify Demodex, Segal $\mathrm{R}$ et $a l$. proposed the use of dermatoscope. The dermoscopy method allows the visualization of mites on skin surface and enlarged skin vessels. However, in this case, there is less information as it is impossible to detect the mites at in-situ localization in the sebaceous glands and in the presence of nodular elements, as well as in macro-abscesses $^{[7]}$. Despite the fact that the "gold standard" for the pathomorphological evaluation of normal and affected skin in dermatology is still a biopsy followed by histological study, there is always a demand in the applied medicine field for informative, high-tech and non-invasive diagnostic methods, which include confocal laser scanning microscopy ${ }^{[8]}$.

Marvin Minski in 1957 patented "scanning microscope with two-stage focus" (termed "confocal", based on having the same foci). In common fluorescence microscope, the mercury or xenon lamp is used as the light source for fluorescence emission; however, in modern confocal microscope, it uses laser. The laser in confocal microscopy was used by P. Davidovich for the first time in 1969. As a source of light in modern confocal microscopes, laser is used for a more accurate work of the optical system of the microscope due to reduced number of reflections in the images, thus providing better focus of the beam of light. A focused laser beam illuminates a certain point of the $\operatorname{skin}^{[9]}$. Due to the specific arrangement of the microscope, the back focus of the condenser -where "confocal" aperture of photo-detector is established-coincides with the front focus of lens and thus obtains images from a very thin layer of an object coined as "optical sections". The work of confocal microscope 
is based mainly on the ability of various structures of the skin to refract the laser light to obtain images of the epidermis and dermis layers ${ }^{[10]}$, and to evaluate the state of the vessels of the skin and dermal fibers ${ }^{[11]}$. In vivo confocal laser scanning microscopy is a new method of studying skin structure through micrograph images that are in the form of white, grey and black shades. Micrograph images of melanocytes and keratinocytes look bright and white, respectively, whereas air and serous fluid look black ${ }^{[12]}$. Confocal laser scanning microscopy allows the determination of skin thickness and the visualization of different layers of the skin. Thus, the method provides additional information concerning composition and structure of the $\operatorname{skin}^{[13]}$. In ophthalmology, it is possible to visualize changes in meibomian glands in the form of extension or obstruction, the presence of inflammatory infiltrates and the detection of Demodex mites ${ }^{[14]}$. The method of confocal laser scanning microscopy can be compared to histological research of the skin with the advantage that this research is carried out non-invasively ${ }^{[10]}$. According to various sources, the sensitivity of the method is $83 \%-91 \%$, while the specificity is $95 \%-99 \%{ }^{[15-17]}$.

The use of confocal laser scanning microscopy in vivo in dermatology is considered one of the most prospective methods today, in spite of the fact that it has several disadvantages (obtaining relatively superficial images up to 200 microns which limits the possibility of research of deeper skin layers, absence of the possibility of obtaining vertical images, high cost of the equipment and its operation and, consequently, the inaccessibility to a larger number of dermatologists ${ }^{[11,18]}$.

In comparison to conventional light microscopy, the advantages of confocal laser scanning microscopy method are, for instance, due to its high-contrast images with high resolution, three-dimensional reconstruction, and digital data processing ${ }^{[12,17]}$. One of the advantages of this method is its ability to detect and quantify Demodex folliculorum on the face of patients with rosacea and acne by counting the mites and follicles per unit area. Sattler EC et al. examined the skin of patients with rosacea and described the presence of Demodex in the form of round or long cone-shaped structure ${ }^{[19]}$. Kojima $\mathrm{T}$ et al. demonstrated the use of confocal laser scanning microscopy for the diagnosis of eye affected with Demodex ${ }^{[20]}$. The authors were able to detect mites in the terminal of eyelash bulbs, causing inflammatory infiltrates around the meibomian glands and conjunctiva.

Thus, confocal laser scanning microscopy is considered as a non-invasive and rapid method for detecting mites of the genus Demodex based on scientific findings in literatures ${ }^{[21]}$. Considering the relevance of this subject as discussed above, we have conducted an examination on healthy volunteers and patients suffering with acne and rosacea through confocal laser scanning microscopy in vivo means. The aim of the research is to assess the impact of Demodex via clinical manifestation of acne and rosacea, and to compare the efficiency of demodecosis diagnosis in patients with acne and rosacea by various methods.

\section{Materials and methods}

Under our supervision, there were 60 patients suffering from acne and rosacea complicated with demodecosis (group I), 60 patients suffering from acne and rosacea without demodecosis (group II) and 30 healthy volunteers (group III). Diagnosis of acne and rosacea was established based on clinical manifestation of the diseases.

Statistical analysis was performed using SPSS 21 software package. The relationship between categorical indicators was established with the use of Fisher's exact test. Fisher's exact test is a test reflecting statistical significance, used in the analysis of categorical data when sample sizes are small. In order to assess the significance differences in the size of the follicles, both the one-way analysis of variance (ANOVA test) and paired comparisons analysis was used. In order to assess the degree of acne's severity, the classification of the American Academy of Dermatology was followed as below:

I degree-the presence of comedones (opened and closed) and up to 10 papules;

II degree-comedones, papules, up to 5 pustules;

III degree-comedones, papulopustules rash, up to 5 nodules;

IV degree-pronounced inflammatory reaction in the deeper layer of the dermis, with the formation of multiple painful nodules and cysts.

The symptoms of rosacea's severity were assessed through its clinical and morphological classifications:

erythematous;

papular;

pustules;

infiltrative-productive.

All respondents were examined for the presence of Demodex by scraping the contents of sebaceous glands, epilation of eyebrows and eyelashes. Using confocal laser scanning microscope VivaScope $1500^{\circledR}$ (Lucid Inc., Rochester, NY), the research was conducted at three points of interest (both cheeks and forehead).

Distribution of the groups in terms of age, gender and diagnosis are presented in Table 144 men and 106 
women, with the mean age of $29.6 \pm 10.3$ years old, participated in the study. Criteria of patients' inclusion in group I and II are: patients had been diagnosed with acne and rosacea existence, age 18 years and above, and gave informed consent before their participation in the study. Exclusion criteria from the study were namely the existence of concurrent somatic diseases of a heavy current or neoplastic character, alcohol or drug addiction, patient's lack of desire to continue with the study, occurrence of allergic reactions, development of significant side effects during treatment, and pregnancy and lactation. Criteria for inclusion in group III: age 18 years and above, with absence of any skin and somatic diseases of a heavy current or neoplastic character.

Table 1. Distribution of groups by age, gender and diagnosis

\begin{tabular}{|c|c|c|c|c|c|}
\hline & & $\begin{array}{c}\text { Group } \\
\text { I }\end{array}$ & $\begin{array}{c}\text { Group } \\
\text { II }\end{array}$ & $\begin{array}{l}\text { Group } \\
\text { III }\end{array}$ & Total \\
\hline \multicolumn{2}{|c|}{$\begin{array}{c}\text { Age } \\
\text { (years) }\end{array}$} & $\begin{array}{c}33.7 \pm \\
13.0\end{array}$ & $\begin{array}{c}28.3 \pm \\
12.0\end{array}$ & $\begin{array}{c}26.9 \pm \\
6.03\end{array}$ & $\begin{array}{c}29.6 \pm \\
10.3\end{array}$ \\
\hline \multirow{2}{*}{ Gender } & male & $\begin{array}{c}24 \\
(40 \%)\end{array}$ & $\begin{array}{c}14 \\
(23 \%)\end{array}$ & $\begin{array}{c}6 \\
(20 \%)\end{array}$ & 44 \\
\hline & female & $\begin{array}{c}36 \\
(60 \%)\end{array}$ & $\begin{array}{c}46 \\
(77 \%)\end{array}$ & $\begin{array}{c}24 \\
(80 \%)\end{array}$ & 106 \\
\hline \multirow{2}{*}{ Diagnosis } & acne & $\begin{array}{c}40 \\
(67 \%)\end{array}$ & $\begin{array}{c}34 \\
(57 \%)\end{array}$ & - & 74 \\
\hline & rosacea & $\begin{array}{c}20 \\
(33 \%)\end{array}$ & $\begin{array}{c}26 \\
(43 \%)\end{array}$ & - & 46 \\
\hline \multicolumn{2}{|l|}{ Total } & $\begin{array}{c}60 \\
(100 \%)\end{array}$ & $\begin{array}{c}60 \\
(100 \%)\end{array}$ & $\begin{array}{c}30 \\
(100 \%)\end{array}$ & 150 \\
\hline
\end{tabular}

The presence of mites was confirmed by scraping the contents of sebaceous glands, epilation of eyebrows and eyelashes. Scraping was conducted using a sterile lancet at places with greatest congestion of sebaceous glands, which are located on the face - forehead, nose, chin and cheeks. The received material was placed on a glass slide, with a drop of $10 \% \mathrm{KOH}$ solution (potassium hydroxide) applied onto it and then viewed under a microscope. The number of mites per $1 \mathrm{~cm}^{2}$ were counted. The diagnosis of demodecosis was considered valid if the contamination of mites on the skin was more than 5 mites on $1 \mathrm{~cm}^{2}$, or if there are more than 4 mites on the eyelashes. During microscopy evaluation, mites from the genus Demodex, i.e., Demodex folliculorum longus and Demodex folliculorum brevis, were found.

A research using confocal laser scanning microscope VivaScope $1500^{\circledR}$ (Lucid Inc., Rochester, NY) was carried out at three points (both cheeks and forehead) in two operating modes of a microscope, i.e., VivaBlock and VivaStack. The patients' skin was visualized in the form of $5 \times 5 \mathrm{~mm}$ size, with laser power of $21.7 \mathrm{~mW}$. By means of confocal microscopy, quantification of mites in the follicles was carried out, during which, the average size of follicles and Demodex mites were determined in depth. For statistical analysis, the Fischer's exact test and the one-way ANOVA test were used.

\section{Results}

Clinical characteristics of patients are presented in Table 2 and Table 3. As can be seen in both tables, Demodex was detected more frequently in patients with rosacea than in patients with acne. During analysis, it was found that patients with demodecosis (group I) were dominated with heavier clinical forms of acne and rosacea. This group was marked with III and IV degrees of acne, with papular and pustules forms of rosacea in most cases, and with two patients diagnosed with infiltrative-productive form of rosacea. On the other hand, in group II the superficial forms of the disease revealed I and II degrees of acne with the existence of erythematous form of rosacea. It gives the grounds to assume that the existence of demodecosis complicates the course of acne and rosacea, thereby promoting the development of inflammatory elements. The prevalence of severe forms of acne and rosacea in patients with concomitant diagnosis of demodecosis confirms the need for microscopic diagnosis of Demodex in patients with acne and rosacea.

Table 2. Distribution of patients with acne depending on the presence of mites and disease severity

\begin{tabular}{|c|c|c|c|c|}
\hline \multirow{2}{*}{\multicolumn{2}{|c|}{$\begin{array}{c}\text { Disease severity } \\
\text { (degree) }\end{array}$}} & \multicolumn{2}{|c|}{ Presence of Demodex mites } & \multirow{2}{*}{ Total } \\
\hline & & yes & no & \\
\hline \multirow{3}{*}{ I } & Frequency & 6 & 2 & 8 \\
\hline & $\%$ severity & $75.0 \%$ & $25.0 \%$ & $100.0 \%$ \\
\hline & $\%$ complication & $17.6 \%$ & $5.0 \%$ & $10.8 \%$ \\
\hline \multirow{3}{*}{ II } & Frequency & 17 & 4 & 21 \\
\hline & $\%$ severity & $81.0 \%$ & $19.0 \%$ & $100.0 \%$ \\
\hline & $\%$ complication & $50.0 \%$ & $10.0 \%$ & $28.4 \%$ \\
\hline \multirow{3}{*}{ III } & Frequency & 11 & 22 & 33 \\
\hline & $\%$ severity & $33.3 \%$ & $66.7 \%$ & $100.0 \%$ \\
\hline & $\%$ complication & $32.4 \%$ & $55.0 \%$ & $44.6 \%$ \\
\hline \multirow{3}{*}{ IV } & Frequency & 0 & 12 & 12 \\
\hline & $\%$ severity & $0.0 \%$ & $100.0 \%$ & $100.0 \%$ \\
\hline & $\%$ complication & $0.0 \%$ & $30.0 \%$ & $16.2 \%$ \\
\hline \multirow{3}{*}{ Total } & Frequency & 34 & 40 & 74 \\
\hline & $\%$ severity & $45.9 \%$ & $54.1 \%$ & $100.0 \%$ \\
\hline & $\%$ complication & $100.0 \%$ & $100.0 \%$ & $100.0 \%$ \\
\hline
\end{tabular}

As can be seen in Table 2, Demodex is detected in patients with acne who had more severe forms of the disease in most cases (the significance difference of Fisher's 
Table 3. Distribution of patients with rosacea depending on the presence of mites and disease severity

\begin{tabular}{|c|c|c|c|c|}
\hline \multicolumn{2}{|c|}{ Type of disease } & \multicolumn{2}{|c|}{$\begin{array}{c}\text { Presence of } \\
\text { Demodex mites }\end{array}$} & \multirow[t]{2}{*}{ Total } \\
\hline & & yes & no & \\
\hline & Frequency & 18 & 4 & 22 \\
\hline \multirow[t]{3}{*}{$\begin{array}{l}\text { Erythematous- } \\
\text { telangiectatic }\end{array}$} & $\%$ severity & $81.8 \%$ & $18.2 \%$ & $100.0 \%$ \\
\hline & $\%$ complication & $69.2 \%$ & $20.0 \%$ & $47.8 \%$ \\
\hline & Frequency & 6 & 10 & 16 \\
\hline \multirow[t]{3}{*}{ Papules } & $\%$ severity & $37.5 \%$ & $62.5 \%$ & $100.0 \%$ \\
\hline & $\%$ complication & $23.1 \%$ & $50.0 \%$ & $34.8 \%$ \\
\hline & Frequency & 2 & 4 & 6 \\
\hline \multirow[t]{3}{*}{ Pustules } & $\%$ severity & $33.3 \%$ & $66.7 \%$ & $100.0 \%$ \\
\hline & $\%$ complication & $7.7 \%$ & $20.0 \%$ & $13.0 \%$ \\
\hline & Frequency & 0 & 2 & 2 \\
\hline \multirow{3}{*}{$\begin{array}{l}\text { Infiltrative- } \\
\text { productive }\end{array}$} & $\%$ severity & $0.0 \%$ & $100.0 \%$ & $100.0 \%$ \\
\hline & $\%$ complication & $0.0 \%$ & $10.0 \%$ & $4.3 \%$ \\
\hline & Frequency & 26 & 20 & 46 \\
\hline \multirow[t]{2}{*}{ Total } & $\%$ severity & $56.5 \%$ & $43.5 \%$ & $100.0 \%$ \\
\hline & $\%$ complication & $100.0 \%$ & $100.0 \%$ & $100.0 \%$ \\
\hline
\end{tabular}

exact test was $p=0.001$ ). Depending on the types ofrosacea, the incidence of mites of the genus Demodex is statistically significant. As shown in Table 3, mites were detected in severe forms of rosacea: papular, pustules and infiltrative-productive (the significance difference of Fisher's exact test was $p=0.004$ ).

In determining the species of Demodex, it was revealed that patients with acne bore different species of Demodex which can also be in the combination of two types of mites. In over half of the cases $(N=33 ; 82.5 \%)$ Demodex folliculorum longus was identified, $10 \%(N=$ 4) had Demodex folliculorum brevis while both species of mites were found in $7.5 \%(N=3)$ (Table 4). In most cases, patients with rosacea revealed the existence of Demodex folliculorum longus $(N=14 ; 70 \%)$ (Table 5).

In situations where more severe forms of acne were found, the presence of Demodex folliculorum longus was often detected significantly (the significance of Fisher's exact test was $p=0.004$ ). As can be seen in Table 5, the mite species were significantly dependent on the clinical form of the disease, which had not been revealed previously (the significance difference of Fisher's exact test was $p=0.354)$. However, by analyzing the data in Table 4 and Table 5, it is apparent that the mites Demodex fol liculorum longus were more often detected in patients

Table 4. Species of Demodex mites in patients with acne depending on the severity of the disease (group I)

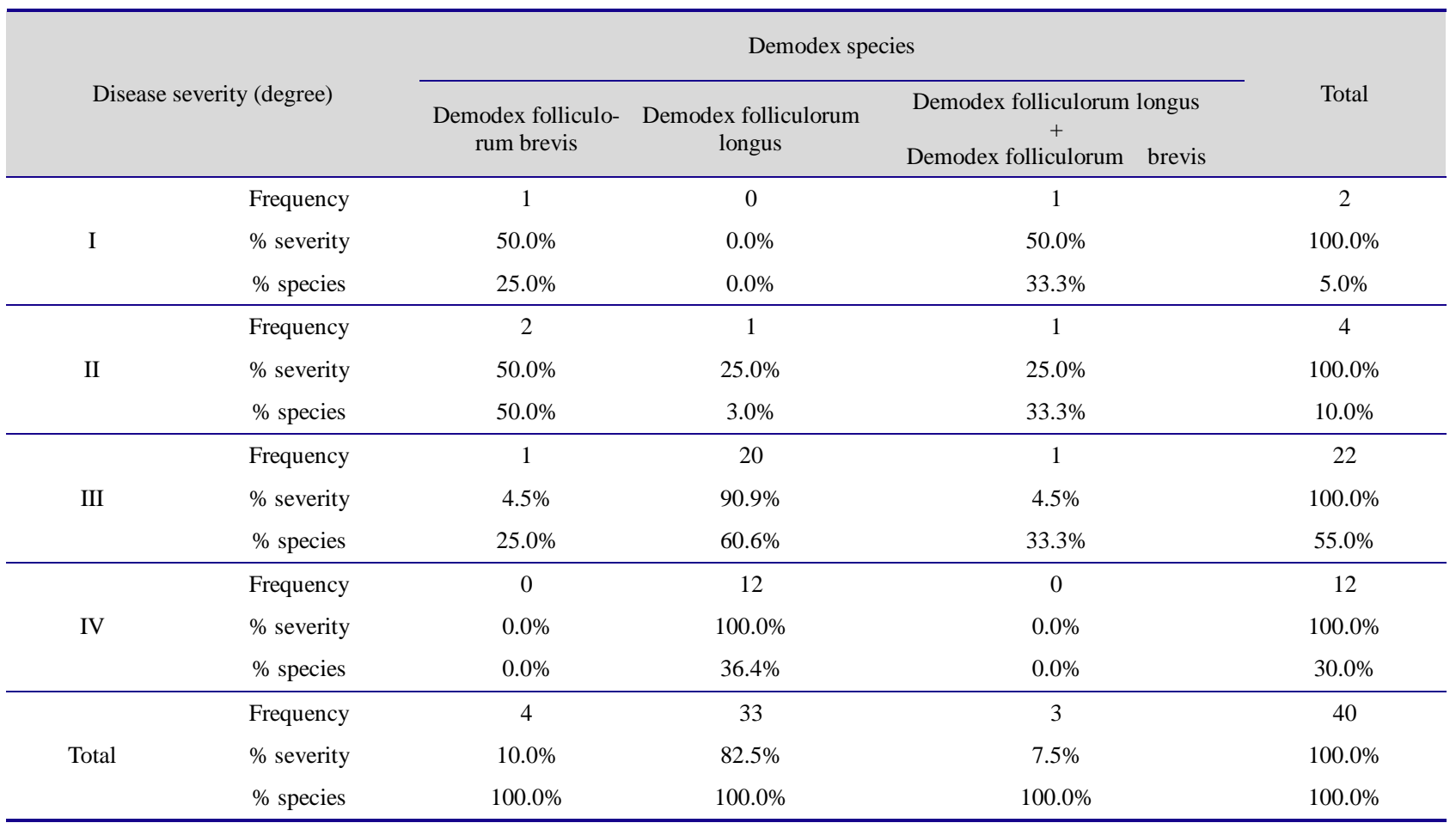


Table 5. Species of Demodex mites in patients with rosacea depending on the clinical form (group I)

\begin{tabular}{|c|c|c|c|c|c|}
\hline \multirow{2}{*}{\multicolumn{2}{|c|}{ Clinical form of the disease }} & \multicolumn{3}{|c|}{ Demodex species } & \multirow[b]{2}{*}{ Total } \\
\hline & & $\begin{array}{l}\text { Demodex folliculorum } \\
\text { brevis }\end{array}$ & $\begin{array}{l}\text { Demodex folliculorum } \\
\text { longus }\end{array}$ & $\begin{array}{c}\text { Demodex folliculorum longus }+ \\
\text { Demodex folliculorum brevis }\end{array}$ & \\
\hline \multirow{3}{*}{$\begin{array}{l}\text { Erythematous } \\
\text { form }\end{array}$} & Frequency & 2 & 1 & 1 & 4 \\
\hline & $\%$ severity & $50.0 \%$ & $25.0 \%$ & $25.0 \%$ & $100.0 \%$ \\
\hline & $\%$ species & $50.0 \%$ & $7.1 \%$ & $50.0 \%$ & $20.0 \%$ \\
\hline \multirow{3}{*}{ Papules form } & Frequency & 2 & 7 & 1 & 10 \\
\hline & $\%$ severity & $20.0 \%$ & $70.0 \%$ & $10.0 \%$ & $100.0 \%$ \\
\hline & $\%$ species & $50.0 \%$ & $50.0 \%$ & $50.0 \%$ & $50.0 \%$ \\
\hline \multirow{3}{*}{ Pustules form } & Frequency & 0 & 4 & 0 & 4 \\
\hline & $\%$ severity & $0.0 \%$ & $100.0 \%$ & $0.0 \%$ & $100.0 \%$ \\
\hline & $\%$ species & $0.0 \%$ & $28.6 \%$ & $0.0 \%$ & $20.0 \%$ \\
\hline \multirow{3}{*}{$\begin{array}{l}\text { Infiltrative- } \\
\text { productive form }\end{array}$} & Frequency & 0 & 2 & 0 & 2 \\
\hline & $\%$ severity & $0.0 \%$ & $100.0 \%$ & $0.0 \%$ & $100.0 \%$ \\
\hline & $\%$ species & $0.0 \%$ & $14.3 \%$ & $0.0 \%$ & $10.0 \%$ \\
\hline \multirow{3}{*}{ Total } & Frequency & 4 & 14 & 2 & 20 \\
\hline & $\%$ severity & $20.0 \%$ & $70.0 \%$ & $10.0 \%$ & $100.0 \%$ \\
\hline & $\%$ species & $100.0 \%$ & $100.0 \%$ & $100.0 \%$ & $100.0 \%$ \\
\hline
\end{tabular}

with acne of III and IV degrees and with papular and pustules forms of rosacea. Therefore, we can assume that it is Demodex folliculorum longus that provokes more severe clinical forms of acne.

In order to assess the reliability of the method using confocal microscopy, the survey was conducted in all three groups. The obtained data are presented in Table 6 and shows not only high information content of the method, but also its superiority over the microscopic diagnosis. As can be seen in the table, the mites were found in all patients with demodecosis using the confocal laser scanning microscopy. Demodex was defined as rounded or long cone-shaped formations in hair follicle orifices and sebaceous glands (Figure 1).

During the inspection on patients from group III, the mites were successfully identified in 10 patients $(13 \%)$,
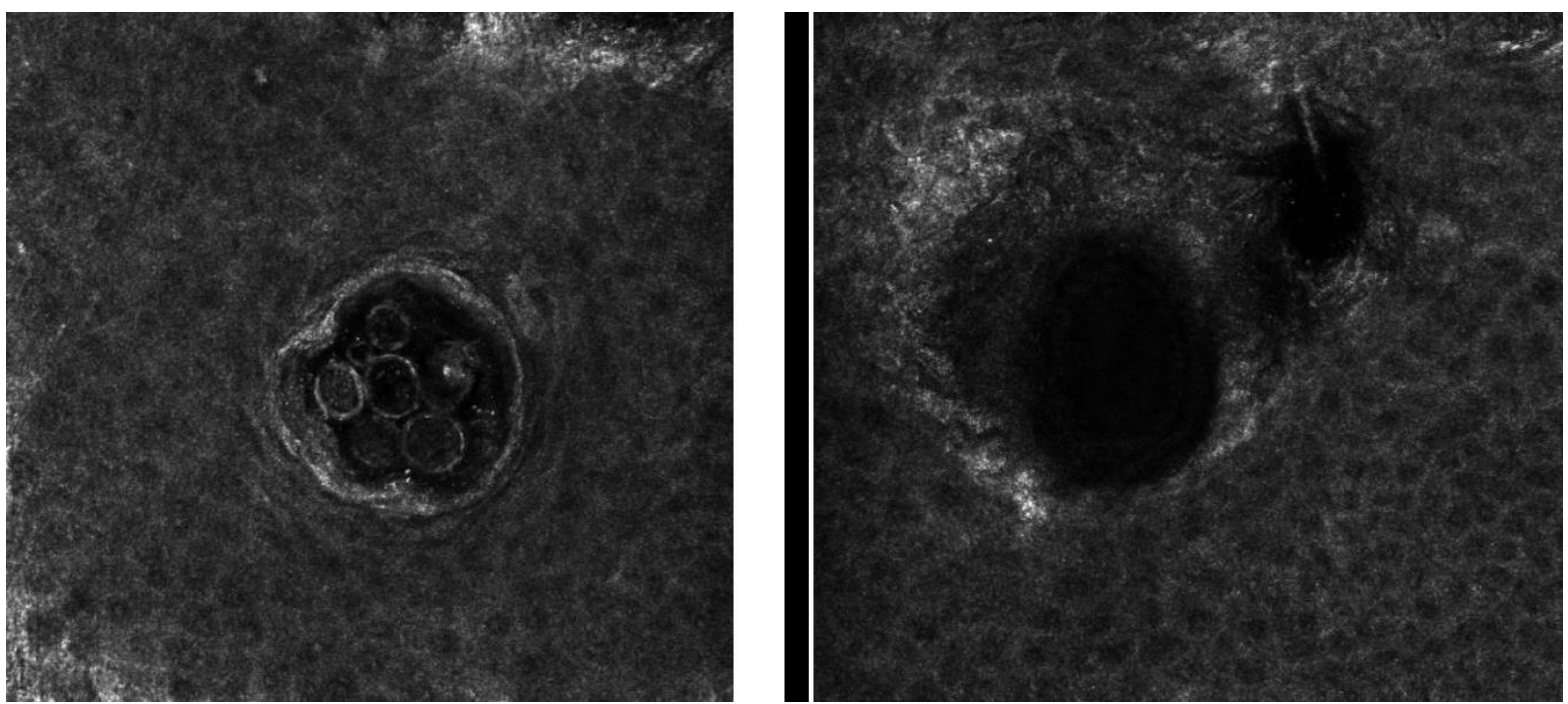

Figure 1. Images obtained using confocal laser scanning microscope VivaScope $1500^{\circledR}$ (Lucid Inc., Rochester, NY). Hair follicles and sebaceous glands with the presence (left) and absence (right) of Demodex mites 
Table 6. Identification of Demodex mites with different diagnostic methods

\begin{tabular}{|c|c|c|c|c|}
\hline $\begin{array}{l}\text { Identification of } \\
\text { Demodex folliculorum }\end{array}$ & $\begin{array}{c}\text { Group I } \\
\text { (number } \\
\text { of patients; \%) }\end{array}$ & $\begin{array}{c}\text { Group II } \\
\text { (number of } \\
\text { patients; \%) }\end{array}$ & $\begin{array}{l}\text { Group III } \\
\text { (number of } \\
\text { patients; \%) }\end{array}$ & $\begin{array}{c}\text { Total } \\
\text { (number of } \\
\text { patients; \%) }\end{array}$ \\
\hline \multirow{2}{*}{$\begin{array}{l}\text { Demodex folliculorum } \\
\text { longus detected }\end{array}$} & 47 & \multirow{2}{*}{-} & \multirow{2}{*}{-} & 47 \\
\hline & $(62 \%)$ & & & $(62 \%)$ \\
\hline \multirow{2}{*}{$\begin{array}{l}\text { Demodex folliculorum } \\
\text { brevis detected }\end{array}$} & 8 & \multirow{2}{*}{-} & \multirow{2}{*}{ - } & 8 \\
\hline & $(10.5 \%)$ & & & $(10.5 \%)$ \\
\hline \multirow{2}{*}{$\begin{array}{l}\text { Two types of } \\
\text { mites detected }\end{array}$} & 5 & \multirow{2}{*}{ - } & \multirow{2}{*}{-} & 5 \\
\hline & $(6.5 \%)$ & & & $(6.5 \%)$ \\
\hline \multirow{2}{*}{$\begin{array}{l}\text { Detected with confocal } \\
\text { laser scanning microscope }\end{array}$} & 60 & 10 & 6 & 76 \\
\hline & $(79 \%)$ & $(13 \%)$ & $(8 \%)$ & $(100 \%)$ \\
\hline \multirow{2}{*}{ Total } & 60 & 10 & 6 & 76 \\
\hline & $(79 \%)$ & $(13 \%)$ & $(8 \%)$ & $(100 \%)$ \\
\hline
\end{tabular}

of whom the method of scraping has shown negative result (Table 6). The study from healthy volunteers of group III found Demodex mites in follicles of 6 people $(8 \%)$ by using the method of confocal laser scanning microscopy. These data confirmed the assumptions of numerous authors that mites can be saprophytes ${ }^{[4]}$. Thus, the study proves to be a highly informative method, as it allows the discovery of mites especially in depths inaccessible for scarification.

By using confocal laser scanning microscope to scan different layers of the skin, we established an average detection depth of mites which equals to approximately 46.63 microns, and corresponds to the level of the granular layer of the epidermis. This method allowed the calculation of the average number of Demodex in the follicle $(N=3.37)$ and the average size of Demodex (which is equal to 0.024 microns). Interesting data were obtained at the size measurement of follicle orifices. It was established that the sizes of follicle orifices in all three groups were authentically different (Table 7 and Table 8).

The differences in sizes of hair follicle orifices and excretory ducts of sebaceous glands in group I were found to be statistically significant, exceeding the sizes in groups II and III. When comparing the sizes of hair follicle orifices and excretory ducts of sebaceous glands of groups II and III, the differences were not statistically significant. The largest size of the orifices was found in patients with demodecosis. This fact makes it possible to assume that a large pore size is a favorable condition for infestation of the mites.

Table 7. Sizes of hair follicle orifices in the studied groups

\begin{tabular}{ccc}
\hline \multicolumn{2}{l}{ Sizes of hair follicular orifices and excretory ducts of sebaceous glands (Mean $\pm \mathrm{sd}$ ) } & \\
\hline Group I & Group II & Group III \\
$0.125 \pm 25 \times 0.123 \pm 35$ & $0.89 \pm 32 \times 0.095 \pm 31$ & $0.065 \pm 23 \times 0.072 \pm 29$ \\
\hline
\end{tabular}

Table 8. Size differences of hair follicle orifices and excretory ducts of sebaceous glands among groups

\begin{tabular}{ccc}
\hline Size differences of hair follicle orifices and excretory ducts of sebaceous glands & Group II and III \\
\hline Group I and II & Group I and III & $0.11 \times 0.29$ \\
$0.012 \times 0.017$ & $0.007 \times 0.009$ & \\
\hline
\end{tabular}

\section{Discussion}

The study demonstrated that demodecosis is often diagnosed in patients with severe clinical forms of acne and rosacea. This fact suggests that the mites complicate the course of the diseases, and thus promoting the development of inflammatory elements. This once again confirms that in order to achieve effective treatment on these dermatoses, there is a need for diagnostic advancement for Demodex mites. 
In the analysis, the mites' species were found to be significantly dependent on the clinical form of the disease; however, the Demodex folliculorum longus mites were more often detected in patients with acne of III and IV degrees and with papular and pustular rosacea. Thus, we can assume that Demodex folliculorum longus provokes more severe clinical forms of acne.

The obtained data proved to have high informational content of confocal microscopy in view of its diagnostic advantages on demodecosis and its superiority over light microscope. Confocal laser scanning microscope makes it possible to visualize mites that are both found in the deeper layers of the skin and inaccessible to scarification. This method has a high potential to be a diagnostic means for demodecosis, which makes it possible to scan various layers of the skin that allows the determination of the depth of mite detection ( $\approx 46.63$ microns), number of mites and also their size. The lack of epithelium trauma and painful procedures are other additional advantages of this method.

\section{Conclusion}

Thus, as a result of research on patients with acne, rosacea and healthy volunteers, we established high informational content of confocal laser scanning microscopy in the diagnosis of demodecosis and its advantages over the usual light microscope.

\section{Conflict of interest}

The authors declared no potential conflict of interest with respect to the research, authorship, and/or publication of this article.

\section{References}

1. Chen W, Plewig G. Human demodecosis: Revisit and a proposed classification. Br J Dermatol 2014; 170(6): 12191225. doi: 10.1111/bjd.12850.

2. Whiting DA. Diagnostics and predictive value of horizontal sections of scalp biopsy specimen in male pattern androgenic alopecia. J Am Acad Dermatol 1993; 28(5 Part 1): 755-763. doi: 10.1016/0190-9622(93)70106-4.

3. Akilov OE, Butov YS, Mamcuoglu KY. A clinic-pathological approach to the classification of human demodecosis. J Dtsch Dermatol Ges 2005; 3(8): 607-614. doi: 10.1111/ j.1610-0387.2005.05725.x.

4. Sirmays NS, Abesadze GA, Ustinov MV. Demodekoz: patogeneticheskie aspekty pri razlichnykh dermatozakh litsa: Metodicheskoe posobie (Russian) [Demodecosis: pathogenic aspects in various facial dermatoses: Methodological guidelines]. Moscow: Gel'tek-Medika; 2013. p. 26.
5. Crawford GH, Pelle MT, James WD. Rosacea: I. Etiology, pathogenesis, and subtype classification. J Am Acad Dermatol 2004; 51(3): 327-341. doi: 10.1016/j.jaad.2004.03. 030 .

6. Bonnar E, Eustace P, Powell FC. Demodex mite in normal skin. Lancet 1991; 337(8750): 1168. doi: 10.1016/ 0140-6736(91)92841-O.

7. Segal R, Mimouni D, Feuerman H, Pagovitz O, David M. Report: Dermoscopy as a diagnostic tool in demodicidosis. Int J Dermatol 2010; 49(9): 1018-1023. doi: 10.1111/ j.1365-4632.2010.04495.x.

8. Astner S, Dietterle S, Otberg N, Röwert-Huber HJ, Stockfleth $\mathrm{E}$, et al. Clinical applicability of in vivo fluorescence confocal microscopy for noninvasive diagnosis and therapeutic monitoring of nonmelanoma skin cancer. J Biomed Opt 2008; 13(1): 014003. doi: 10.1117/1.2837411.

9. Psaty EL, Halpern AC. Current and emerging technologies in melanoma diagnosis: The state of the art. Clin Dermatol 2009; 27(1): 35-45. doi: 10.1016/j.clindermatol.2008.09. 004.

10. Rajadhyaksha M. Confocal reflectance microscopy: Diagnosis of skin cancer without biopsy? In: National Academy of Engineering (editors). Frontiers of Engineering: Reports on Leading Edge Engineering From the 1998 NAE Symposium on Frontiers of Engineering. Washington: National Academies Press; 1999. p. 24-33. doi: 10.17226/6411.

11. Nwaneshiudu A, Kuschal C, Sakamoto FH, Anderson RR, Schwarzenberger $\mathrm{K}$, et al. Introduction to confocal microscopy. J Invest Dermatol 2012; 132(12): 1-5. doi: 10. 1038/jid.2012.429.

12. Kubanova AA, Chikin VV, Shtirshneider YY, Katunina OR. Confocal laser scanning microscopy in vivo for diagnosing melanocytic skin neoplasms. Vestnik dermatologii i venerologii 2014; 3: 85-94.

13. Neerken S, Lucassen GW, Lenderink E, Nuijs TAM. In vivo imaging of human skin: A comparison of optical coherence tomography and confocal laser scanning microscopy. In: Tuchin VV, Izatt JA, Fujimoto JG (editors). Proc. SPIE 4956, Coherence Domain Optical Methods and Optical Coherence Tomography in Biomedicine VII, 299; 2003 Jan 25; San Jose CA. 2003. doi: 10.1117/12.478948.

14. Messmer EM, Torres Suárez E, Mackert MI, Zapp DM, Kampik A. In vivo confocal microscopy in blepharitis. Klin Monbl Augenheilkd 2005; 222(11): 894-900. doi: 10.1055/ s-2005-858798.

15. Nori S, Rius-Diaz F, Cuevas J, Goldgeier M, Jaen P, et al. Sensitivity and specificity of reflectance-mode confocal microscopy for in vivo diagnosis of basal cell carcinoma: a multicenter study. J Am Acad Dermatol 2004; 51(6): 923930. doi: 10.1016/j.jaad.2004.06.028.

16. Gerger A, Koller S, Kern T, Massone C, Steigner K, et al. Diagnostic applicability of in vivo confocal laser scanning microscopy in melanocytic skin tumors. J Invest Dermatol 2005; 124(3): 493-498. doi: 10.1111/j.0022-202X.2004. 
23569.x.

17. Gerger A, Koller S, Weger W, Richtig E, Kerl H, et al. Sensitivity and specificity of confocal laser-scanning microscopy for in vivo diagnosis of malignant skin tumors. Cancer 2006; 107(1): 193-200. doi: 10.1002/cncr.21910.

18. Shtirshnayder YY, Michenko AV, Katunina OR, Zubarev AR. New non-invasive imaging technology in dermatology. Vestnik dermatologii i venerologii 2011; 5: 41-53.

19. Sattler EC, Maier T, Hoffmann VS, Hegyi J, Ruzicka T, et al. Noninvasive in vivo detection and quantification of Demodex mites by confocal laser scanning microscopy.
Br J Dermatol 2012; 167(5): 1042-1047. doi: 10.1111/ j.1365-2133.2012.11096.x.

20. Kojima T, Ishida R, Sato EA, Kawakita T, Ibrahim OMA, et al. In vivo evaluation of ocular demodecosis using laser scanning confocal microscopy. Invest Ophthalmol Vis Sci 2011; 52(1): 565-569. doi: 10.1167/iovs.10-5477.

21. Erdemir AT, Gurel MS, Koku Aksu AE, Bilgin Karahalli F, Incel $\mathrm{P}$, et al. Reflectance confocal microscopy vs. standardized skin surface biopsy for measuring the density of Demodex mites. Skin Res Technol 2014; 20(4): 435-439. doi: 10.1111/srt.12137. 